\title{
In vivo graft performance of an improved bone substitute composed of poor crystalline hydroxyapatite based biphasic calcium phosphate
}

\author{
Ching-Lien HUNG 5 , Jen-Chang YANG ${ }^{3}$, Wei-Jen CHANG ${ }^{1}$, Chih-Yuan $\mathrm{HU}^{3}$, Yong-Ho LIN${ }^{4}$, Chun-Hsien HUANG ${ }^{3}$, \\ Chien-Chung $\mathrm{CHEN}^{3}$, Sheng-Yang LEE ${ }^{1,2}$ and Nai-Chia TENG ${ }^{1,2}$ \\ ${ }^{1}$ School of Dentistry, College of Oral Medicine, Taipei Medical University, 250 Wu-Hsing Street, Taipei, Taiwan, ROC \\ ${ }^{2}$ Dental Department of Wan-Fang Hospital, Taipei Medical University, 250 Wu-Hsing Street, Taipei, Taiwan, ROC \\ ${ }^{3}$ Graduate Institute of Biomedical Materials \& Engineering, College of Oral Medicine, Taipei Medical University, 250 Wu-Hsing Street, Taipei, Taiwan, \\ ROC \\ ${ }^{4}$ Department of Pathology, Taipei Medical University Hospital, 250 Wu-Hsing Street, Taipei, Taiwan, ROC \\ ${ }^{5}$ Department of Dentistry, Shin Kong Wu Ho-Su Memorial Hospital, No. 95, Wen Chang Road, Taipei, Taiwan, ROC \\ Corresponding author, Nai-Chia TENG; E-mail: dianaten@tmu.edu.tw
}

\begin{abstract}
The ability to promote new bone formation of poor crystalline hydroxyapatite (PC-HA) based biphasic calcium phosphate (BCP) bone substitutes were investigated. Various ratios of porous PC-HA/ $\beta$-TCP (70/30, 60/40, and 0/100) grafts were fabricated. SEM and XRD measurements were performed to study the morphology and crystalline structure. Cylindrical artificial bone defects $\left(3 \times 6 \mathrm{~mm}^{2}\right)$ were produced in alveolar bone at premolars extraction site and then filled with sterilized bone grafts. Commercial MBCP $^{\circledR}$ and unfilled empty defect served as control groups. At 8 weeks postoperation, samples were harvested from each artificial defect site for histological analysis. New bone formation of all the PC-HA/ $\beta$-TCP groups was significantly greater than that of the empty control group ( $p<0.05$ ), but without statistical difference from that of $\mathrm{MBCP}^{\circledR}$ group. The degree of uniformity of new bone formation within defect region for $\mathrm{PC}-\mathrm{HA} / \beta$-TCP $(60 / 40)$ was higher than that for $\mathrm{MBCP}^{\mathbb{B}}$. The PC-HA/ $\beta$-TCP grafts showed enhanced bone regenerations with a more even dispersion of new bone formation than the other materials without causing inflammation, suggesting that these materials may be an alternative choice for bone void fillers in dental applications.
\end{abstract}

Keywords: Biphasic calcium phosphate, Bone graft, Hydroxyapatite, $\beta$-tricalcium phosphate, In vivo

\section{INTRODUCTION}

Bone grafts are clinically used as a void filler to accelerate the healing of large defects through new bone formation and structural support. Although many types of bone grafts are currently available for bone repair, they all have significant limitations in their chemistry, architecture, and mechanical properties. New materials which more closely mimic the properties of bone itself need to be developed. Autograft, allograft, and synthetic materials comprise the currently available choices in clinics to repair bone in orthopedic, spinal, and craniomaxillofacial (dental) surgeries ${ }^{1-3)}$. Among them, autogeneous bone remains the "gold standard" of substitution material which fulfills physicochemical and biological properties, with limitations of post-operative pain and availability. However, the most common alternatives to autogeneous bone graft -allografts and xenografts have the disadvantages of infectivity or unfavorable immune response, while synthetic materials have a low osteogenic capacity but are a safe source to apply in clinical use ${ }^{4}$.

Synthetic calcium phosphate ceramics have chemical components and structure similar to those of minerals in bone and teeth. For an ideal bone-grafting material to be replaceable by new bone, it needs to be both biodegradable and osteoconductive. Two of the most widely tested types of materials are hydroxyapatite (HA) and $\beta$-tricalcium

Color figures can be viewed in the online issue, which is available at J-STAGE.

Received Apr 30, 2010: Accepted Aug 17, 2010

doi:10.4012/dmj.2010-060 JOI JST.JSTAGE/dmj/2010-060 phosphate $(\beta$-TCP). Both of these osteoconductive bioceramics bond tightly with bone ${ }^{5-8}$, but HA is less resorbable than $\beta$-TCP ${ }^{9,10}$. A mixture of $\mathrm{HA}$ and $\beta$-TCP produces biphasic calcium phosphate (BCP) which possesses the reactivity of $\beta$-TCP and the stability of HA, providing more bioactivity, involving more new bone growth, and ensuring better resistance of the implants to strain $^{11-13)}$. BCP has an intermediate resorbability which can be controlled by variation of the $\mathrm{HA} / \beta$-TCP ratio. Despite the many advantages of BCP ceramic systems, the ideal ratio of $\mathrm{HA} / \beta$-TCP for in vivo bone replacement remains unclear, and their biodegradation rate range still does not satisfy the requirement for biodegradable biomaterials ${ }^{10,14,15)}$.

Despite recent successes of synthetic calcium phosphates, their performance requires improvement. A well-known strategy is to add biological factors to induce bone formation, to stimulate angiogenesis, or even to make osteogenic hybrids by adding cells. However, rather than adding these costly and complex factors, improvement of the physico-chemical properties so that they instruct their in vivo environment would be a better approach. Relatively rapid biodegradation of synthetic bone substitutes is desirable because residual particles that may interfere with bone creeping substitution process ${ }^{16)}$. Low-crystalline HA shows higher resorption ability $^{17,18)}$ which is very different from the theoretical density of HA. This is due to the poor development of the crystal, which results in crystalloid defects that then exhibit different characteristics such as increased 
solubility and resorption rate after implantation in vivo. By controlling the particulate size and crystallinity of HA and/or calcium phosphate-based bone substitutes, materials with a strong ability to attract bone cells can be developed.

The purpose of this study was to evaluate a new resorption rate enhancing biphasic calcium phosphate bone graft material which contain low-crystalline HA and $\beta$-TCP (PC-HA/ $\beta$-TCP), and to compare them with a commercially available product $\left(\mathrm{MBCP}^{\circledR}\right)$. Biological performance was assessed using histological specimens of implants in the alveolar bone of Beagle dogs. Ratio of new bone formation was evaluated histomorphometrically.

\section{MATERIALS AND METHODS}

This study was conducted in the animal center affiliated with National Pingtung University of Science and Technology. Four mature Beagle dogs with weight between $8-12 \mathrm{~kg}$ and age between 2-3 years old, with healthy general and oral condition served as the experimental animals. They were kept under a standard light-dark schedule and relative humidity. All procedures were approved by the Animal Research Committee of Taipei Medical University.

\section{Preparation of implants}

PC-HA and $\beta$-TCP powders were synthesized by the wet chemical method: for preparing poor crystalline hydroxyapatite (PC-HA), we added $370 \mathrm{~g}$ calcium hydroxide $\left(\mathrm{Ca}(\mathrm{OH})_{2}\right.$, J.T. Baker Inc. USA) into $1,000 \mathrm{~mL}$ distilled water (DDW). Then, the $\mathrm{Ca}(\mathrm{OH})_{2}$ aqueous solution was mixed with 13 liters of DDW into a reactor. The $24.3 \mathrm{w} / \mathrm{v} \%$ phosphoric acid $\left(\mathrm{H}_{3} \mathrm{PO}_{4}\right.$, J.T Baker Inc. USA) $1,000 \mathrm{~mL}$ were dropped slowly into the solution of $\mathrm{Ca}(\mathrm{OH})_{2}$. The reaction is under a stirring rate of 500-700 rpm at $20^{\circ} \mathrm{C}$ for 24 hours. After reaction finished, the solution was filtered and dried at $80^{\circ} \mathrm{C}$ for 24 hours.

$\beta$-TCP was prepared by wet-chemical reaction methods. Concentration of $\mathrm{CaCO}_{3}$ (Riedel de Haen Inc.) and $\mathrm{CaHPO}_{4}$ (Riedel de Haen Inc.) were prepared as 86.0 $\mathrm{w} / \mathrm{v} \%$ in 1,000 $\mathrm{mL} \mathrm{DDW}$ and $25 \mathrm{w} / \mathrm{v} \%$ in 1,000 $\mathrm{mL} \mathrm{DDW,}$ respectively. They were mixed under stirring rate of 500-700 rpm for 24 hours. Then the solution was filtered and dried at $80^{\circ} \mathrm{C}$ for 24 hours then sintered at $1150^{\circ} \mathrm{C}$ and pulverized to become as $\beta$-TCP granules.

The PC-HA and $\beta$-TCP were chose in different ratio such as 60/40, 70/30. The composites were blended, pressed, sintered 24 hours at $1150^{\circ} \mathrm{C}$ and cooling down to ambient temperature. The blocks of PC-HA $\beta$-TCP were pulverized into granules with particle size ranged 500-1,000 $\mu \mathrm{m}$. The composition of macroporous biphasic calcium phosphate bone substitute $\left(\mathrm{MBCP}^{\circledR}\right.$, Biomatlante, Vigneux de Bretagne, France) is HA/ $\beta$-TCP (60/40). Implants were placed in glass bottles and sterilized by ultraviolet irradiation (wave length: 250-260 nm) before implantation.

\section{Characterization of Materials}

1. SEM analysis

Sample surfaces were sputter coated with carbon using an E-1010 Ion Sputter (HITACHI, Japan), and the microstructure was observed by scanning electron microscopy (SEM) (S-2400 HITACHI, Japan) at $15 \mathrm{kV}$, with a magnification of $1,000 \times$.

2. X-ray diffraction (XRD) analysis

Implants were dried and ground for XRD (MaxRC, Rigaku, Japan, $10^{\circ} \mathrm{min}, 2 \theta$ from $5^{\circ}$ to $60^{\circ}$ ) studies. The phase composition was checked using Joint Committee on Powder Diffraction standards.

3. Crystallite size analysis

The peak broadening of XRD reflection can be used to estimate the crystallite size in a direction perpendicular to the crystallographic plane based on Scherrer's formula as follows ${ }^{19)}$ :

\section{$X \mathrm{~s}=0.9 \lambda /(\mathrm{FWHM} \times \cos \theta)$}

where $X_{\mathrm{s}}$ is the crystallite size $[\mathrm{nm}] ; \lambda$ is the wavelength of monochrome X-ray beam $(\mathrm{nm})(\lambda=0.15406$ $\mathrm{nm}$ for $\mathrm{CuK}_{a}$ radiation); and FWHM is the full width at half maximum for the diffraction angle $\left(^{\circ}\right)$. The diffraction peak at $2 \theta=25.9^{\circ}$ was chosen for calculation of the crystallite size since it is sharper and isolated from the others. This peak assigns to (002) Miller's plane family and shows the crystal growth along the $c$-axis of the HA crystalline structure. The value of $X$ s was calculated for the PC-HA/ $\beta$-TCP powders synthesized with different compositions based on this diffraction peak using Scherrer's formula.

\section{Surgical procedure}

Four Beagle dogs were obtained from the National Pingtung University of Science and Technology (Pingtung, Taiwan). Prior to the implantation of bone grafts, all premolars of the Beagle dogs were extracted to create the same edentulous area. After 16 weeks of healing, bone graft implantations were performed on the four animals under general anesthesia. Ten minutes before anesthesia, an intramuscular sedative injection of $0.01 \mathrm{mg} / \mathrm{kg}$ Ketalar was given. General anesthesia was induced by intravenous injection of $12.5 \mathrm{mg} / \mathrm{kg}$ sodium thiopenthal and preserved by halothane inhalation. An intravenous injection of $1 \mathrm{~g}$ cefalexine was given for preoperative antibiotic prophylaxis. Cylindrical osseous defects of 3-mm-diameter and 6-mm-length were surgically created in bilateral maxillar (two per animal, one per side) and mandibular (four per animal, two per side) alveolar bone. The implant samples (PC-HA $\beta$ $\mathrm{TCP}=70 / 30,60 / 40,0 / 100$, and $\mathrm{MBCP}^{\circledR}$ ) were then inserted into the created defects. The same surgical procedure was performed in the control group without insertion of any material.

The implanted sites were conglutinated with resorbable sutures for primary healing. Operated areas and general states of the animals were checked daily according to standard veterinary postoperative care. 


\section{Histological evaluation}

After the surgery, the operation wound condition, contour of the bone flap, allergy or rejection reaction to the material, and other complications were investigated at time periods of $2,4,6$, and 8 weeks. Histology specimens were all collected at 8 weeks after the surgery for evaluation of new bone formation, inflammatory reactions, and other complications. 5-mm-diameter and 8-mm-length cylindrical osseous samples were harvested and fixed in $10 \%$ buffered formalin, decalcified with rapid decalcification formulation ( $\mathrm{RDF})$, embedded, sectioned at $8 \mu \mathrm{m}$ thickness, and stained with hematoxylin and eosin (H\&E).

\section{Histomorphometry}

Histomorphometry of was investigated on photomicrographs of four samples from each group. Newly formed bone measurements were made by analysis of light microscope photographs (Nikon, ALPHAPHOT-2/YS2, Japan) exported from a digital camera (Coolpix4500, Nikon, Japan) and quantitatively analyzed by ImageJ 1.37c software (National Institutes of Health (NIH), Bethesda, MD, USA; freeware from http://rsb.info.nih.gov/ij). The contiguity of the microscopy photographs were checked by the juxtaposition of the 9 fields placed side by side at $80 \times$ magnification. New bone formation rate was calculated as a percentage: (Area of total defect site of vision-Area of total cavities due to bone graft occupation)/Area of total defect site of vision) $\times 100$.

\section{Statistical analysis}

Quantitative differences among the explants from each group were assessed by one way ANOVA. Individual differences between controls and explants with materials were determined by Duncan's multiple range tests and $\mathrm{CV}$ (coefficient of variation) ${ }^{20)}$. Statistical significance was established at $p<0.05$.

\section{RESULTS}

Material characteristics

1. SEM analysis

In Figure $1, \mathrm{PC}-\mathrm{HA} / \beta$-TCP at ratios of $70 / 30$ and $60 / 40$

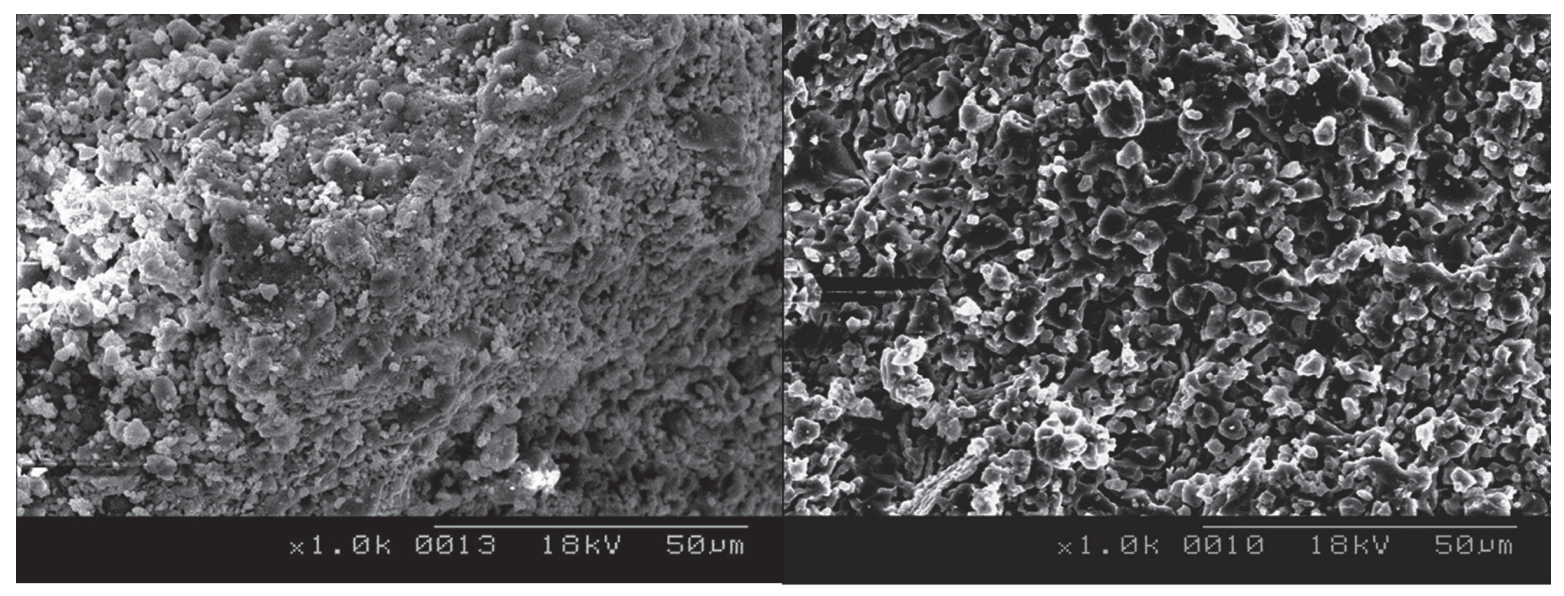

(a)PC-HA/ $\beta-T C P=60 / 40$

(b)PC-HA/ $\beta-T C P=70 / 30$

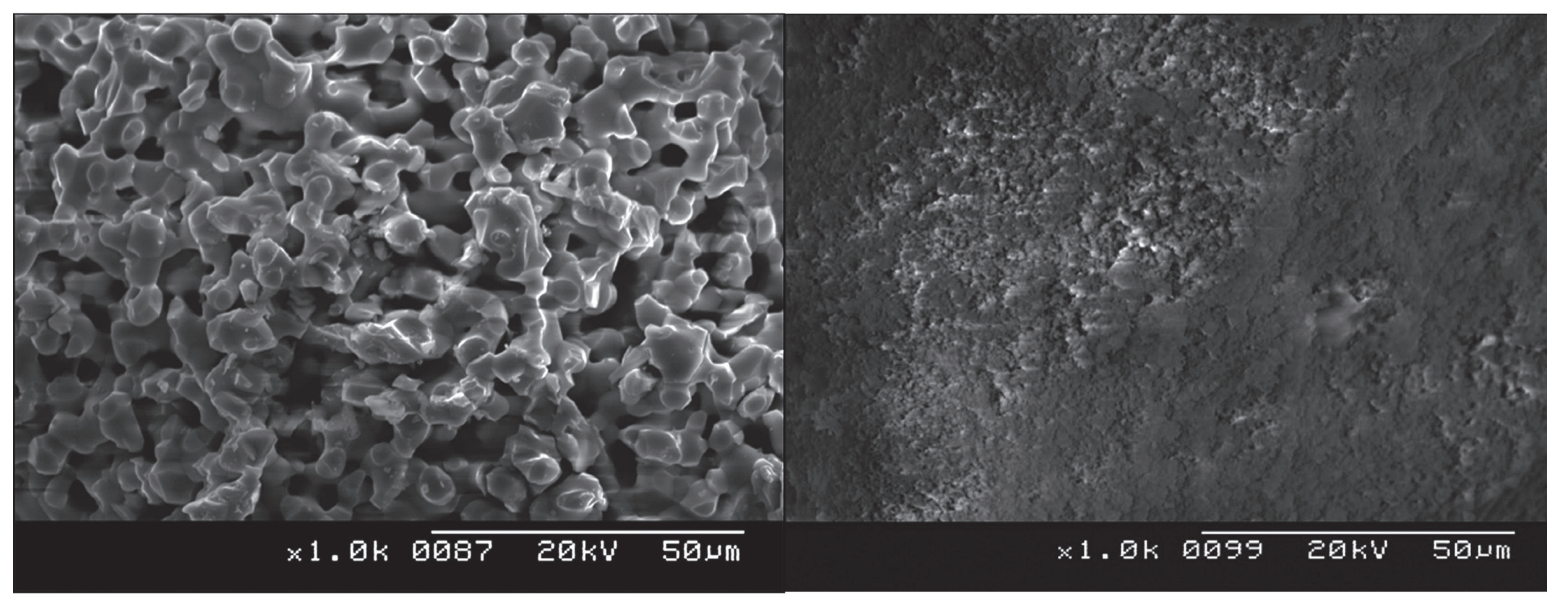

\section{(c) $\beta-T C P=100 \%$}

Fig. 1 Scanning electron microscopy of the implants (c) $\beta-\mathrm{TCP}=100 \% ;(\mathrm{d}) \mathrm{MBCP}^{\circledR}(1,000 \times)$. (d) $M B C P ®(1,000 X)$

(a) $\mathrm{PC}-\mathrm{HA} / \beta-\mathrm{TCP}=60 / 40 ; \quad$ (b) $\mathrm{PC}-\mathrm{HA} / \beta-\mathrm{TCP}=70 / 30$; 


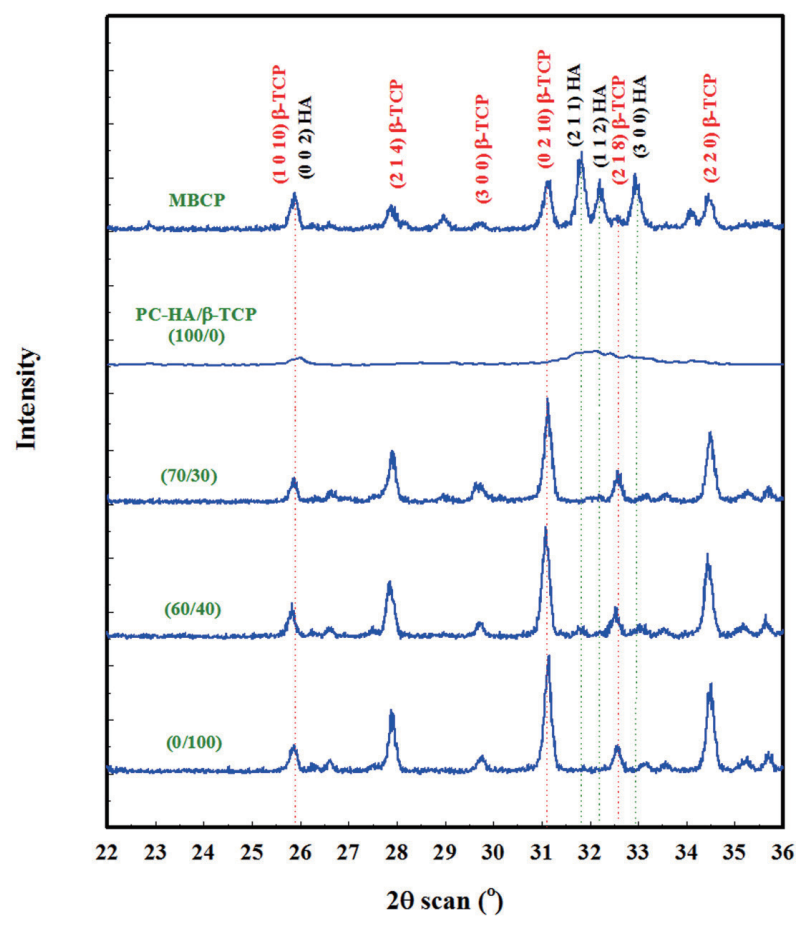

Fig. 2 X-ray diffraction pattern of poor crystalline-HA (PC-HA), $\quad \mathrm{MBCP}^{\circledR}, \quad \mathrm{PC}-\mathrm{HA} / \beta-\mathrm{TCP}=60 / 40, \quad 70 / 30$, and $\beta$-TCP (100\%).

Table 1 Crystallite size of different graft materials

\begin{tabular}{lcc}
\hline & $\begin{array}{c}\text { Diffraction } \\
\text { angle } 2 \theta\left(^{\circ}\right)\end{array}$ & $\begin{array}{c}\text { Crystallite size } \\
\text { Xs }(\mathrm{nm})\end{array}$ \\
\hline $\mathrm{PC}-\mathrm{HA} / \beta$-TCP $=70 / 30$ & 25.87 & 42.9 \\
$\mathrm{PC}-\mathrm{HA} / \beta-\mathrm{TCP}=60 / 40$ & 25.96 & 56.3 \\
$\mathrm{MBCP}^{\circledR}$ & 25.88 & 39.5 \\
$\beta$-TCP & 25.87 & 40.6 \\
\hline
\end{tabular}

and $\mathrm{MBCP}^{\circledR}$ showed typical particle sizes within $500-1,000 \mu \mathrm{m}$. PC-HA/ $\beta$-TCP at ratios of $60 / 40$ and $70 / 30$ showed larger macroporosity than $\mathrm{MBCP}^{\circledR}$, but smaller particle size and macroporosity than pure $\beta$-TCP, which may influence the infiltration of the fibrovascular tissue and revascularization.

2. XRD analysis

Analysis of XRD spectra revealed the samples contained a mixture of apatite, HA and $\beta$-TCP (Figure 2). Typical diffraction peaks related with $\mathrm{HA}$ are $25.90^{\circ}\left(\begin{array}{lll}0 & 0 & 2\end{array}\right)$, $31.86^{\circ}$ (2 11 1), $32.20^{\circ}$ (1 12 2), and $32.90^{\circ}$ (3 00 ); while the diffraction peaks of $\beta$-TCP are $27.81^{\circ}$ (2 14$), 31.01^{\circ}$ (2 1 $10)$ and $34.31^{\circ}(220)$. A closer look at the peak intensities related with both HA and $\beta$-TCP were clearly detectable in $\mathrm{MBCP}^{\circledR}$. For PC-HA along, the HA peak intensity was relatively low. Due to the low crystallinity of PC-HA, only the $\beta$-TCP could be detected from XRD for

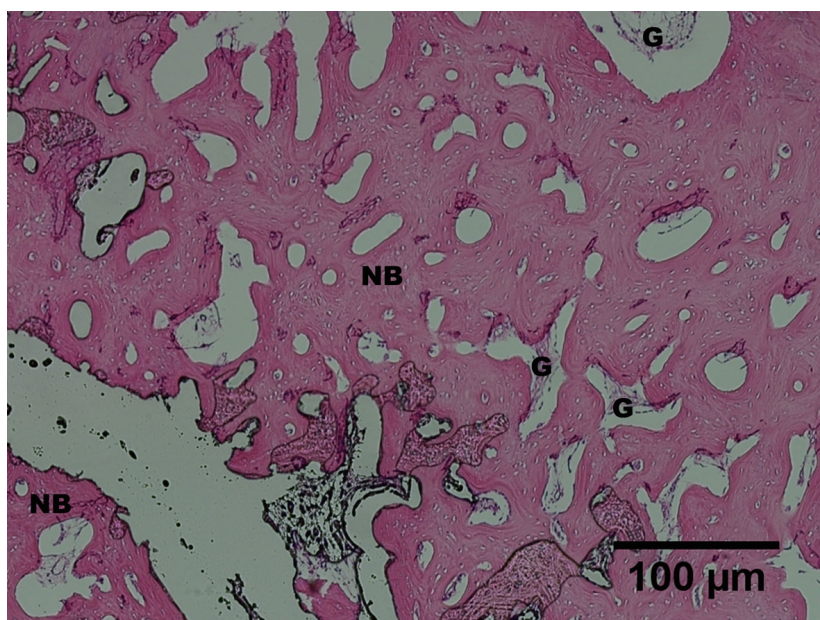

Fig. 3 Photomicrograph of $\mathrm{PC}-\mathrm{HA} / \beta-\mathrm{TCP}=70 / 30$ at 8 weeks after implantation. (NB: new bone, G: graft)

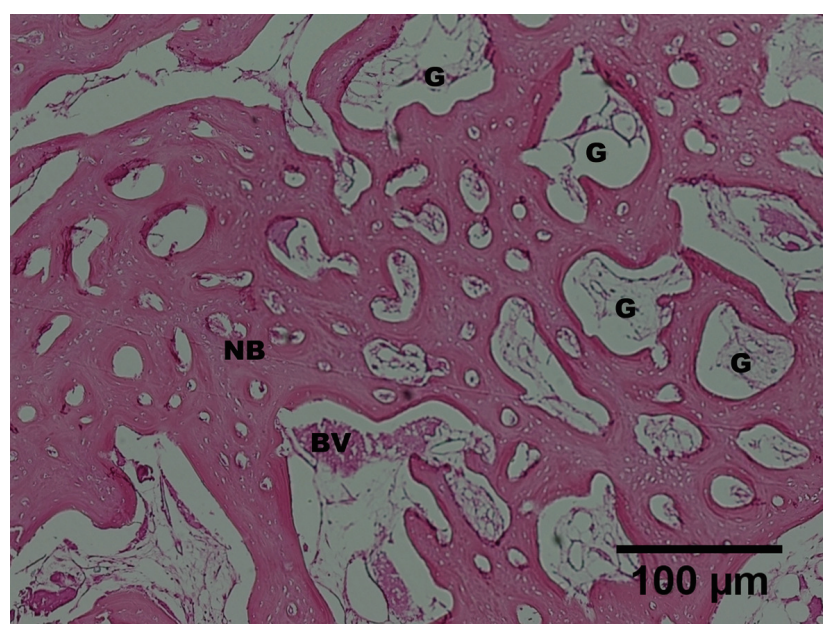

Fig. 4 Photomicrograph of $\mathrm{PC}-\mathrm{HA} / \beta-\mathrm{TCP}=60 / 40$ at 8 weeks after implantation. (NB: new bone, G: graft)

$\mathrm{PC}-\mathrm{HA} / \beta$-TCP at ratios of $70 / 30,60 / 40$ and $0 / 100$.

Further investigation of the crystallite size of the samples using Scherrer's formula showed that the crystallite size in $\mathrm{MBCP}^{\circledR}$ was the smallest among the four materials (Table 1).

\section{Clinical observations}

Biphasic calcium phosphate bone grafts were implanted and examined using a standardized maxillar and mandibular model. Only minor complications were observed during the surgery. All animals survived without general or localized complications during 8 weeks after the operation. All sites healed uneventfully and no infectious complications or gingival inflammation around implanted area were found during the experimental period. 


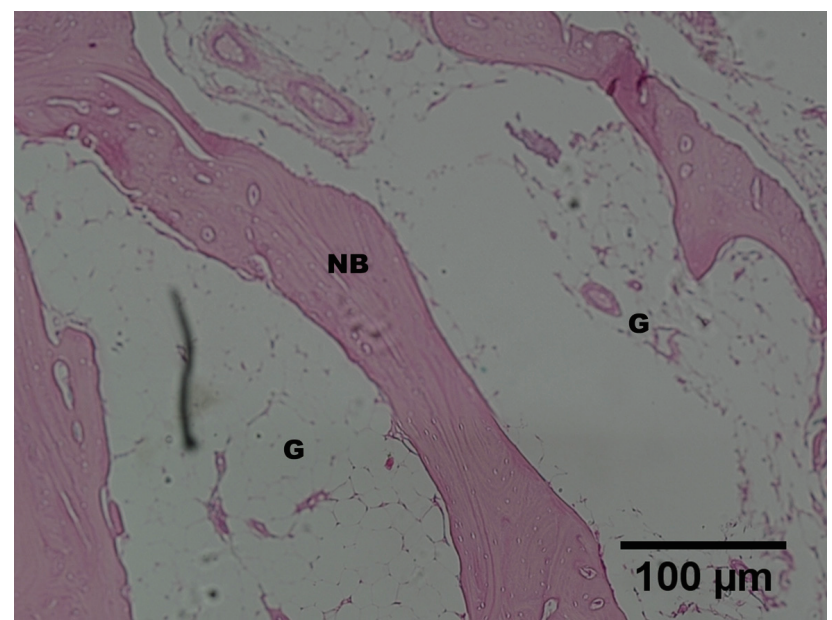

Fig. 5 Photomicrograph of $\mathrm{MBCP}^{\circledR}$ at 8 weeks after implantation. (NB: new bone, G: graft)

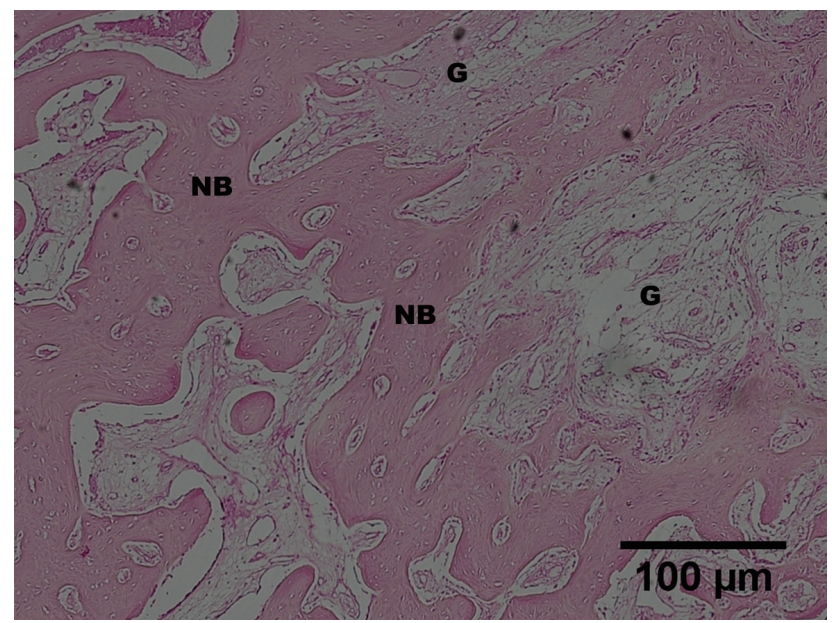

Fig. 6 Photomicrograph of $\beta$-TCP at 8 weeks after implantation. (NB: new bone, G: graft)

\section{Histomorphologic study}

All implanted and control sites healed uneventfully with no clinical evidence of inflammatory response to the ceramic implant. Extensive evidence of osteoconduction was found in the experimental groups. New bone was deposited directly on the surface of peripheral pores in all PC-HA $\beta$-TCP and commercial products, and a harversian structure was often apparent.

All of the samples with bone graft materials developed more new bone formation in comparison with the empty control group. The amount of bone regeneration and material replacement appeared to be greater in the specimens with PC-HA/ $\beta$-TCP ratios of $70 / 30$ and $60 / 40$ compared with other treatments. Duncan's multiple range test showed that all treatments produced significantly more new bone formation than the empty control group $(p<0.05)$. Two of the "active" treatment

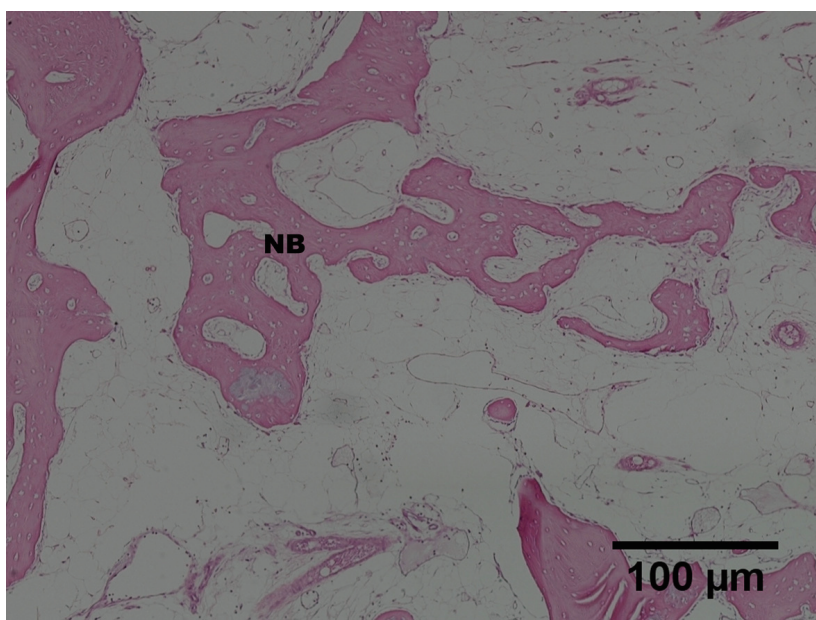

Fig. 7 Photomicrograph of empty control at 8 weeks after implantation. (NB: new bone, ST: soft tissue, OB: old bone)

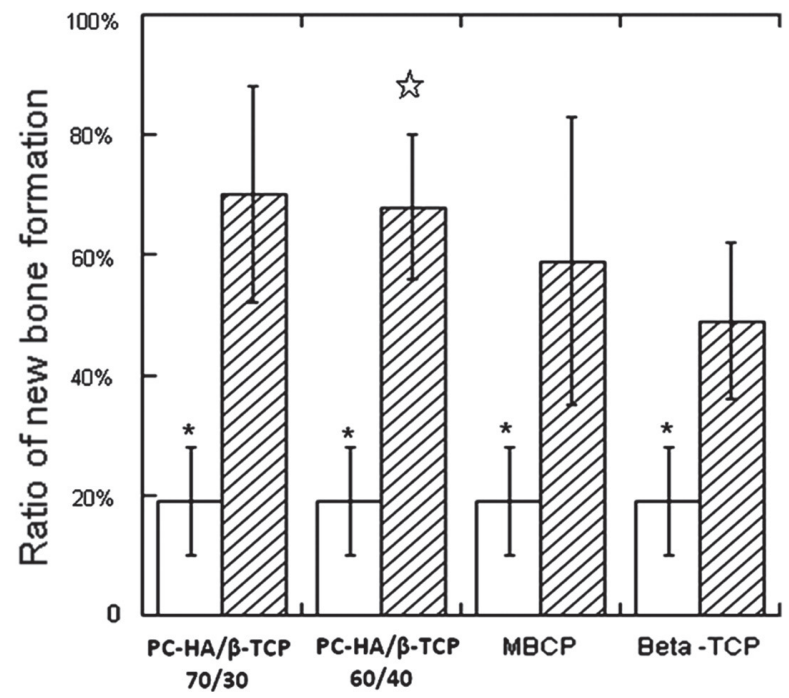

Fig. 8 Histomorphometric data of new bone formation in each group. Blank bar is for empty control group. Data are means \pm standard deviation $(n=4) * p<0.05$ vs. control group determine by one way ANOVA, is $p<0.05$ vs. $\beta$-TCP group analyzed by Duncan's multiple range test.

groups (PC-HA/ $\beta$-TCP=70/30 and 60/40) had significantly more new bone formation than the $100 \% \beta$-TCP group $(p<0.05)$ (Figure 8).

Figures 3 and 4 illustrate that the new bone formation around the ceramic particles and the trabecular pattern of the newly formed bone in specimens of the groups with $\mathrm{PC}-\mathrm{HA} / \beta$-TCP ratios of $70 / 30$ and $60 / 40$ was different from that in the $\mathrm{MBCP}^{\circledR}$ specimens (Figure 5). Smaller cavities were observed more often in the groups with $\mathrm{PC}-\mathrm{HA} / \beta$-TCP ratios of $70 / 30$ and $60 / 40$ compared to the $\mathrm{MBCP}^{\circledR}$ and $\beta$-TCP groups (Figures 5 and 6). These were blood-vessel-like cavities accompanied 
Table 2 Percentage of newly formed bone for different kinds of implants

\begin{tabular}{lcc}
\hline & $\begin{array}{c}\text { Ratio of new } \\
\text { bone formation } \\
\text { Mean (S.D.) }\end{array}$ & $\begin{array}{c}\text { New bone CV } \\
(\%)\end{array}$ \\
\hline $\mathrm{PC}-\mathrm{HA} / \beta-\mathrm{TCP}=70 / 30$ & $0.702(0.180)$ & 25.56 \\
$\mathrm{PC}-\mathrm{HA} / \beta-\mathrm{TCP}=60 / 40$ & $0.681(0.117)$ & 17.14 \\
$\mathrm{MBCP}^{\circledR}$ & $0.592(0.242)$ & 40.83 \\
$\beta$-TCP & $0.494(0.130)$ & 26.29 \\
Empty control & $0.189(0.086)$ & 45.64 \\
\hline
\end{tabular}

by osteoblasts and trabecular bone characteristic of new bone regeneration.

Most of the ceramic particles were found in larger cavities, and could be observed more easily in the $\mathrm{MBCP}^{\circledR}$ and $\beta$-TCP groups. A greater number of remaining ceramic particles demonstrated a slower resorption rate, which indicates a decrease in osteoblastic activity and delay of new bone replacement.

The mean percentage of newly formed bone for each group is shown in Table 2 . The new bone ratio (new bone area/total area) and the coefficient of variation (CV) of the new bone ratio were calculated to analyze the extent of dispersion of new bone in the implanted sites. The histomorphologic results showed the new bone formation ratio in the various groups is as following: $\mathrm{PC}-\mathrm{HA} / \beta$ $\mathrm{TCP}=70 / 30(70.23 \%)>\mathrm{PC}-\mathrm{HA} / \beta-\mathrm{TCP}=60 / 40(68.10 \%)>\mathrm{MB}$ $\mathrm{CP}^{\circledR}(59.17 \%)>\beta-\mathrm{TCP}(49.41 \%)>$ empty control $(18.92 \%)$.

\section{DISCUSSION}

For biomedical applications, hydroxyapatite (HA) and tricalcium phosphate or the combination of both termed BCP are most frequently used. Based on differences in chemical properties such as calcium to phosphate ratio, crystallinity, sintering, and physical forms such as granules/blocks, coating or cement or geometry like porosity ${ }^{21-23)}$, the subtle differences in these parameters can have a serious effect on the biological outcome. One of the parameters influencing the bone regenerative outcome of a synthetic BCP bone graft substitute is its phase composition. Osteoinductive potential is increased by increasing the specific surface area and by the presence of more soluble calcium phosphate phases ${ }^{24,25)}$.

Important results of Previous BCP in vivo studies were as follows: (1) in ceramic bone grafts, the ratio of biphasic HA and $\beta$-TCP influenced the healing condition of bone defects ${ }^{26)}$; (2) Sintered BCP with different temperature may change the porosity of the ceramics, and it interact differently with biological fluids, cells and tissues ${ }^{27}$; (3)the healing effects of mixing $85 \%$ HA with $15 \% \beta$-TCP or $65 \%$ HA with $35 \% \beta$-TCP were better than those obtained using HA or $\beta$-TCP alone or mixing $50 \%$ HA with $50 \% \beta$-TCP ${ }^{28,29)}$.

This animal study compared an improved BCP
Table 3 Composition of commercial synthetic calcium phosphate products

\begin{tabular}{lcc}
\hline Product name & HA (\%) & $\beta$-TCP $(\%)$ \\
\hline ProOsteon $^{\circledR}$ (Interpore) & 100 & 0 \\
Endobon $^{\circledR}$ (Merck) & 100 & 0 \\
MBCP $^{\circledR}$ (Biomatlante) & 60 & 40 \\
Triosite $^{\circledR}$ (Zimmer) & 60 & 40 \\
BCP $^{\circledR}$ (Bioland) & 60 & 40 \\
Collagraft $^{\circledR}$ (Zimmer) & 60 & 40 \\
Ostilit $^{\circledR}$ (Stryker) & 20 & 80 \\
BoneSave $^{\circledR}$ (Stryker) & 20 & 80 \\
Vitoss Scffold $^{\circledR}$ (Curasan) & 0 & 100 \\
Cerasorb Ortho $^{\circledR}$ (Curasan) & 0 & 100 \\
\hline
\end{tabular}

composed of different ratios of PC-HA with commercial product $\mathrm{MBCP}^{\circledR}$. We hypothesized that $\mathrm{BCP}$ containing PC-HA could be resorbed and replaced more efficiently than the traditional fully crystallized hydroxyapatite. This study had two important findings which support this hypothesis.

First, SEM study showed that PC-HA/ $\beta$-TCP filler had larger pore size and macroporosity than the commercial product $\mathrm{MBCP}^{\circledR}$, which may make it a better scaffold for the ingrowth of bone. A large macroporosity (i.e., 400-600 $\mu \mathrm{m}$ ) facilitates infiltration by fibrovascular tissue and revascularization, allowing bone reconstruction.

Second, comparison of the crystallinity of the PC-HA and $\beta$-TCP ceramics analyzed in this study revealed that $\beta$-TCP peaks were clear at the narrow diffraction peaks of $25.61^{\circ}, 27.81^{\circ}, 31.01^{\circ}$, and $34.31^{\circ}$ in $\beta$-TCP and the PC-HA/ $\beta$-TCP ratios of $70 / 30$ and $60 / 40$, while peaks of $\mathrm{HA}$ were found at the diffraction peaks of $31.86^{\circ}, 32.20^{\circ}$, and $32.90^{\circ}$ in $\mathrm{MBCP}^{\circledR}$ but not obvious in PC-HA (100\%) samples, and were difficult to identify for the PC-HA/ $\beta$-TCP ratios of $70 / 30$ and $60 / 40$. The results of $\mathrm{XRD}$ revealed that the diagrams for the $\mathrm{PC}-\mathrm{HA} / \beta$-TCP ratios of $60 / 40$ and $70 / 30$ were more similar to $\beta$-TCP $(100 \%)$ than $\mathrm{MBCP}^{\circledR}$. Because the peaks of PC-HA were unremarkable, it was difficult to distinguish between samples with $\mathrm{PC}-\mathrm{HA} / \beta$-TCP ratios of $60 / 40,70 / 30$ and $\beta$-TCP (100\%), which explains why PC-HA is poor crystallized and can be resorbed more quickly in physiological environments. Although commercial products of $\mathrm{HA} / \beta$-TCP are available in many different ratios (Table 3 ), our analysis revealed no poor-crystalline HA content in these commercial products.

Based on histomorphologic results, the ratios of new bone formation for the PC-HA/ $\beta$-TCP ratio of $60 / 40$ and $\mathrm{MBCP}^{\circledR}$ were $68.10 \%$ and $59.17 \%$, respectively. Although there was no significant difference in new bone formation 
between $\mathrm{PC}-\mathrm{HA} / \beta$-TCP groups and $\mathrm{MBCP}^{\circledR}$ group, the CV for samples of PC-HA/ $\beta$-TCP (60/40) group was much lower than that for $\mathrm{MBCP}^{\circledR}$ group (17.14 and 40.83, respectively), which indicates that the new bone formation of PC-HA/ $\beta$-TCP (60/40) group had a higher degree of dispersion and PC-HA/ $\beta$-TCP was resorbed more evenly than $\mathrm{MBCP}^{\circledR}$.

Ideally, the rate of resorption, resulting in a sequentially changing bone-biomaterial interface, is similar to the rate of formation of new bone. The advantages of using a bioresorptive material as a bone substitute are obvious. First, remodeling of the newly formed bone is not influenced by the presence of the ceramic. Second, no foreign body remains in place during the rest of the patient's lifetime. Third, after resorption of the ceramic material the remodeled bone is stronger than the combination of a ceramic and newly formed bone. However, the rate of resorption and the mechanism by which resorption takes place remain to be established.

Oonishi et al. reported that the resorption time of HA with a particle size of $100-300 \mu \mathrm{m}$ was too long to allow new bone ingrowths, while $\beta$-TCP with a similar particle size partially resorbed in 6 weeks and provided suitable space for new bone ingrowth. They also noted that low (poor) crystalline HA had better resorption bioactivity in the bone graft area ${ }^{30}$. The better bioresorptive ability obtained using PC-HA instead of crystalline HA in this study support these previous findings. We also found that histological specimens of experimental groups of PC-HA $/ \beta$-TCP had a higher new bone formation rate as shown by the presence of tinier trabecular bones surrounded by blood-vessel-like cavities. This phenomenon suggests that PC-HA resorbed more evenly and quickly in this animal model, and thus may be a better bone replacement material than fullycrystallized HA.

This study showed that PC-HA induced new bone growth in defects with good biocompatibility and without adverse effects. Our results indicate that incorporation of PC-HA in BCP influenced new bone formation. Although the new bone formation area in this study was not significantly different between treatment groups with different ratios of $\mathrm{PC}-\mathrm{HA} / \beta$-TCP, histological analysis revealed that the PC-HA $/ \beta$-TCP groups showed a tendency to greater gain in new bone formation accompanied by more even new bone distribution than the MBCP $^{\circledR}$ and $\beta$-TCP groups. Use of a PC-HA component in the biphasic calcium phosphate (BCP) resulted in greater new bone gain than in the groups that received fully crystallized HA. This may be due to the low dissolution rate of fully crystallized HA. Previous studies reported that fully crystallized HA has no osteoinductive capability, and that it has a "benign" reaction with tissues ${ }^{31}$. Our findings that the combination of PC-HA and $\beta$-TCP resulted in good new bone regeneration suggests that PC-HA plays a more effective role in inducing cell proliferation, revascularization, and osteogenesis, and may have more potential to dissolve in physiological body fluids during the healing process. Furthermore, to examine the relative variability in histological analysis, coefficient of variation (CV), a normalized measure of dispersion of a probability distribution, was introduced. The $\mathrm{CV}$ value of new bone formation ratio for the PC-HA/ $\beta$-TCP of $70 / 30$ and $60 / 40$ groups were much lower than for $\mathrm{MBCP}^{\circledR}$ suggesting that the osteoconductive materials promoting a consistent healing within the defect area, but the more suitable PC-HA/ $\beta$-TCP ratio and sinter environment may need further clinical investigation.

\section{CONCLUSIONS}

This in vivo study compared the new bone formation rate of different mixing ratios of PC-HA/ $\beta$-TCP $(70 / 30,60 / 40$, 0/100) with commercial products of $\mathrm{MBCP}^{\circledR}$ and empty controls. The results showed that PC-HA $/ \beta$-TCP mixture ratios of $70 / 30,60 / 40$ provided better new bone regeneration rate than $\beta$-TCP $(100 \%)$ and empty control groups without any toxic or inflammatory reactions. These findings demonstrate the osteoconductive potential of our synthesized materials. These new BCP bone graft materials may be a more suitable choice for clinical use in bone defects than conventional substitutes, and are worthy of further evaluation.

\section{ACKNOWLEDGMENTS}

We would like to thank BioTech One (Taipei, Taiwan) for supplying the BonaGraft ${ }^{\circledR}$ of pure phase $\beta$-tricalcium phosphate $(\beta$-TCP) as well as poor crystalline hydroxyapatite PC-HA/ $\beta$-TCP (60/40, 70/30). This study was sponsored by the Shin Kong Wu Ho-Su Memorial Hospital (SKH-TMU-92-42).

\section{REFERENCES}

1) Parikh SN. Bone graft substitutes: past, present, future. J Postgrad Med 2002; 48: 142-148.

2) Khan SN, Tomin E, Lane JM. Clinical applications of bone graft substitutes. Orthop Clin North Am 2000; 31: 389-398.

3) Betz RR. Limitations of autograft and allograft: new synthetic solutions. Orthopedics 2002; 25: s561-570

4) Giannoudis PV, Dinopoulos H, Tsiridis E. Bone substitutes: an update. Injury 2005; 36: S20-S27.

5) Jensen SS, Broggini N, Hjorting-Hansen E, Schenk R, Buser D. Bone healing and graft resorption of autograft, anorganic bovine bone and beta-tricalcium phosphate. A histologic and histomorphometric study in the mandibles of minipigs. Clin Oral Implants Res 2006; 17: 237-243.

6) Le Guehennec L, Goyenvalle E, Aguado E, Houchmand-Cuny M, Enkel B, Pilet P, Daculsi G, Layrolle P. Small-animal models for testing macroporous ceramic bone substitutes. $\mathrm{J}$ Biomed Mater Res B 2005; 72: 69-78.

7) Daculsi G, LeGeros RZ, Deudon C. Scanning and transmission electron microscopy, and electron probe analysis of the interface between implants and host bone. Osseo-coalescence versus osseo-integration. Scanning Microsc 1990; 4: 309-314.

8) Jarcho M, Kay JF, Gumaer KI, Doremus RH, Drobeck HP. Tissue, cellular and subcellular events at a bone-ceramic hydroxylapatite interface. J Bioeng 1977; 1: 79-92.

9) Walsh WR, Vizesi F, Michael D, Auld J, Langdown A, Oliver $\mathrm{R}$, Yu Y, Irie H, Bruce W. Beta-TCP bone graft substitutes in a bilateral rabbit tibial defect model. Biomaterials 2008; 29: 
266-271.

10) Habibovic P, Kruyt MC, Juhl MV, Clyens S, Martinetti R, Dolcini L, Theilgaard N, van Blitterswijk CA. Comparative in vivo study of six hydroxyapatite-based bone graft substitutes. J Orthop Res 2008; 26: 1363-1370.

11) Weiss P, Layrolle P, Clergeau LP, Enckel B, Pilet P, Amouriq Y, Daculsi G, Giumelli B. The safety and efficacy of an injectable bone substitute in dental sockets demonstrated in a human clinical trial. Biomaterials 2007; 28: 3295-3305.

12) Le Nihouannen D, Daculsi G, Saffarzadeh A, Gauthier O, Delplace S, Pilet P, Layrolle P. Ectopic bone formation by microporous calcium phosphate ceramic particles in sheep muscles. Bone 2005; 36: 1086-1093.

13) Cavagna R, Daculsi G, Bouler JM. Macroporous calcium phosphate ceramic: a prospective study of 106 cases in lumbar spinal fusion. J Long Term Eff Med Implants 1999; 9: 403-412.

14) Shi H, Ma J, Zhao N, Chen Y, Liao Y. Periodontal regeneration in experimentally-induced alveolar bone dehiscence by an improved porous biphasic calcium phosphate ceramic in beagle dogs. J Mater Sci Mater Med 2008; 19: 3515-3524.

15) Ghosh SK, Nandi SK, Kundu B, Datta S, De DK, Roy SK, Basu D. In vivo response of porous hydroxyapatite and betatricalcium phosphate prepared by aqueous solution combustion method and comparison with bioglass scaffolds. J Biomed Mater Res B 2008; 86: 217-227.

16) Cao W, Hench L. Bioactive materials. Ceramics Int 1996; 22 : 493-507.

17) LeGeros RZ, Shirra WP, Miravite MA, Legeros JP. Amorphous calcium phosphates: synthetic and biological. Paris: Colloque Int CNRS; 1973.

18) LeGeros RZ. Calcium phosphates in oral biology and medicine. Monographs in oral aciences. Karger: Basel; 1991.

19) Pang YX, Bao $X$. Influence of temperature, ripening time and calcination on the morphology and crystallinity of hydroxyapatite nanoparticles. J Euro Ceram Soc 2003; 23: 1697-1704.

20) Romano FL, Ambrosano GMB, Magnani MBBdA, Nouer DF. Analysis of the coefficient of variation in shear and tensile bond strength tests. J Appl Oral Sci 2005; 13: 243-246.
21) Ruhé $P$, Wolke J, Spauwen P, Jansen J. Calcium phosphate ceramics for bone tissue engineering. BocaRaton, FL: CRC; 2005.

22) Bohner M. Calcium orthophosphates in medicine: from ceramics to calcium phosphate cements. Injury 2000; 31 : 37-47.

23) Vaccaro AR. The role of the osteoconductive scaffold in synthetic bone graft. Orthopedics 2002; 25: s571-s578.

24) Habibovic P, Yuan $H$, van den Doel M, Sees TM, van Blitterswijk CA, de Groot K. Relevance of osteoinductive biomaterials in critical-sized orthotopic defect. J Orthop Res 2006; 24: 867-876.

25) Habibovic P, Yuan H, van der Valk CM, Meijer G, van Blitterswijk CA, de Groot K. 3D microenvironment as essential element for osteoinduction by biomaterials. Biomaterials 2005; 26: 3565-3575.

26) Nery EB, LeGeros RZ, Lynch KL, Lee K. Tissue response to biphasic calcium phosphate ceramic with different ratios of HA/beta TCP in periodontal osseous defects. J Periodontol 1992; 63: 729-735.

27) Fellah BH, Gauthier O, Weiss P, Chappard D, Layrolle P. Osteogenicity of biphasic calcium phosphate ceramics and bone autograft in a goat model. Biomaterials 2008; 29: 1177-1188.

28) Kwon S-H, Jun Y-K, Hong S-H, Lee I-S, Kim H-E, Won YY. Calcium phosphate bioceramics with various porosities and dissolution rates. J Amer Ceram Soc 2002; 85: 3129-3131.

29) Farina NM, Guzon FM, Pena ML, Cantalapiedra AG. In vivo behaviour of two different biphasic ceramic implanted in mandibular bone of dogs. J Mater Sci Mater Med 2008; 19: 1565-1573.

30) Oonishi H, Hench LL, Wilson J, Sugihara F, Tsuji E, Kushitani S, Iwaki H. Comparative bone growth behavior in granules of bioceramic materials of various sizes. J Biomed Mater Res B 1999; 44: 31-43.

31) Kamitakahara M, Ohtsuki C, Miyazaki T. Review paper: behavior of ceramic biomaterials derived from tricalcium phosphate in physiological condition. J Biomater Appl 2008; 23: 197-212. 